\title{
El Barroco en la Literatura Mexicana
}

$\mathrm{E}^{\mathrm{L}}$ origen del concepto artístico "barroquismo" no es menos incierto que la etimología de la palabra: Sea que hayamos de reducir la palabra "barrueco" a una de aquellas creaciones artificiales de la edad media que sirvieron de arrimo de la memoria para inculcar los nombres difíciles del silogismo - como lo explica Ludwig Pfandl-, sea que nos remontemos a la etimología más antigua de este vocablo, como una derivación del vocablo latino "veruca", defecto o granillo en alguna piedra preciosa -inter-. pretación completamente abandonada en nuestros días-; sea que sigamos la explicación de Monlau y de Meyer-Luebke, quienes reducen "barrueco" al vocablo latino bis-roca, dando al bis un sentido peyorativo y equivalente a roca defectuosa - el problema de este concepto permanece difícil $\mathbf{y}$ no podemos pretender que todas las raíces del barroquismo han sido descubiertas. Hubo un período en la historia del arte en el cual se consideraba el barroco como decadencia, acompañando los fenómenos de la decadencia y de la corrupción de la sociedad en los siglos XVI y XVII. Fué particularmente el eminente erudito suizo Jacob Burckhardt, cuyo juicio resultó al principio completamente negativo, quien influyó decisivamente en la opinión pública por muchas décadas. No se ha prestado atención suficiente a una carta de Burckhardt escrita en 1875, en que dice: "Mi respeto al barroco está creciendo de hora en hora, y dentro de poco estaré propenso a considerarlo el fin propio y el resultado principal de la arquitectura viva. No tiene solamente posibilidades para explicar todo lo que sirve de objeto fijo, sino tiene también posibilidades para expresar el relumbrón hermoso." 
En una esfera más elevada todos los fenómenos, todas las manifestaciones del espíritu humano se unen en una unidad más alta, como lo ha dicho el erudito francés Henri Delacroix: "Se deben aislar los hechos para hacerlos constar, unificarlos para entenderlos." Claro que las investigaciones de las varias emanaciones del espíritu humano deben hacerse en diversos campos, bajo diversos puntos de vista, $\mathrm{y}$ bajo aspectos varios según los fines diferentes intentados por' estas investigaciones. Empero, en la vida del alma del hombre viene un momento en el cual siente la nostalgia de una unificación de todo lo que ha hallado. Viene el momento en el cual el espíritu del hombre creador quiere gozar de los resultados de las investigaciones particulares, porque la síntesis permanece como fin y última esperanza. Desde este punto de vista desaparecen las distinciones más o menos artifíciales que hemos hecho en interés de nutestra tarea especial. Ahora se ocultan los límites entre los varios campos de la ciencia. Se oculta el problema especial del clasicismo en la poesía, en la arquitectura y en la pintura como un problema aislado; el clasicismo vuelve a ser una manifestación del espiritu humano en su ensimismamiento. $\mathrm{Y}$ hablando del barroco: pierde este fenómeno el carácter particular y aislado, como un problema de formas múltiples de los siglos XVI y XVII; el barroco en esta esfera astume el carácter de una manifestación del alma de una nación o, más correctamente, del alma humana. Bajo este punto de vista, es una línea que une el barroco español con el de México, el manerismo en la pintura italiana (Pontormo) con el manerismo italiano, el preciosismo francés con el eufuísmo inglés. Si consideramos el barroco como una nueva forma, como una superación de una fase cultural antecedente, no podemos más calificarlos sólo como decadencia y error, sino como reacción y nueva expresión de una nueva idea, de un ademán alterado.

Bajo este aspecto no cabe duda que es correcto hablar del barroco en la literatura. La literatura es el espejo del alma humana, y si esta alma produce creaciones banrocas en los campos de las artes, ¿ por qué no hablar de un barroco literario? Esta opinión ha sido subrayada por Helmut Hatzfeld en su excelente estudio sobre "El predominio del espíritu español en la literatura europea del siglo XVII", y el mismo erudito nos da una definición muy clara y completa en las palabras siguientes: 
A nuestro modo de ver, el espiritu $y$ arte españoles tienen afinidad con lo barroco desde los primeros tiempos y se oponen al clasicismo, italianismo, espítitu de armonía, de geometría, de belleza amable; con otras palabras: al equilibrio grecorromano. $Y$ lo que se opone a esos tasgos es el gran ademán de heroismo desmesurado, el paradójico entrelazamiento y asociación de ideas y palabras, el lenguaje' intensamente figurativo, la constante mezcla de religión y sensualidad y los extremos de crueldad y de intolerancia ortodoxa.

¿Cuál es la ventaja de un tal ademán hacia nuestro problema? Considerando el barroco como un fenómeno universal, no tenemos la intención de simplificar artificialmente el problema. Más bien intentamos descubrir las raíces de un espectáculo que alteró no solamente a algunos individuos, sino la apariencia de una sociedad entera. Pero primeramente y sobre todo, representamos el punto de vista del carácter universal del barroco en el interés de la justicia: en el mismo momento en el cual atribuímos un valor positivo al barroco, pierde ese período de la historia humana el carácter puramente negativo atribuído a él por quienes ven en el barroco nada más que decadencia y mal gusto. Todas las personalidades de estos siglos -en Europa como en nuestro continente-, aunque naturalmente no todas vuelven a hacerse poetas de primera clase, aparecen en una luz diversa, si las consideramos como representantes de una ideología nueva, como guías en un período con rumbos cambiados. Todas las señales y designaciones de gongorismo, culteranismo, conceptismo y manerismo pierden su carácter enteramente negativo, y comenzamos a entender mejor las obras de Góngora y de Bocanegra, de Sor Juana y de Sigüenza y Góngora; en suma, gozamos más de las obras artísticas de esta época, nos acercamos a ella con la firme voluntad de tratarla con comprensión y con justicia.

Empero esta intención nos impone una obligación muy seria y. grave: más fácil es hacer constar las debilidades, los aspectos negativos de una época artística, que explicar esta época como una era creadora en el desarrollo del espíritu humano. Los valores positivos del barroco vuelven a ser accesibles a nosotros solamente si sabemos exactamente lo que es el barroco, prescindiendo de los juicios negativos de que hemos hablado antes. Debemos cambiar de rumbo: debemos dejar por un momento la cuestión del barroco 
mexicano y preguntarnos qué es lo barroco en general, para poder aplicar el resultado de esta investigación a nuestro problema particular.

II

Tenemos comparativamente pocos ejemplos de una denominación de aquella era como movimiento barroco. Es Julio Jiménez Rueda quien, en su notable prólogo a la obra de Sor Juana Inés de la Cruz, "Los empeños de una casa", menciona la presencia de este fenómeno cultural. Diciendo que Sor Juana en el siglo XVII $y$ en la corte virreinal fué un claro ejemplo de inteligencia más que de emóción, que "intelectual es la poesía de Sor Juana", prepara su conclusión de que la apariencia substituia a la realidad. "Consecuencia del barroquismo que imperaba en todas las manifestaciones de carácter social y espiritual." Parangonando la obra de la jeronimita con la de don Pedro Calderón, Jiménez Rueda hace constar que los puntos de contacto entre los dos se hallan en el barroco. La respuesta de Sor Juana al obispo de Puebla, Fernández de Santa Cruz, que escribe Sor Juana con el pseudónimo de "Sor Philotea" -iqué pensamiento barroco para un obispo!- es en sí misma una obra maestra del barroquismo intelectual y emocional. El prólogo de Jiménez Rueda demuestra la tesis de este artículo: que el barroco en el siglo XVII subyuga tanto la poesía como la pintura, tanto la arquitectura como el teatro y hasta la filosofía. (P. Gracián.)

Como ha dicho Heinrich Woelfflin, el barroco no posee ninguna teoría. Su fundamento está compuesto de los elementos más diferentes, corriendo siempre el riesyo de someterse a influjos ajenos y bizarros. Muy interesante es la definición -que es al mismo tiempo una caracterización- que se encuentra en la grande Enciclopedia Francesa (tomo 11 del año 1758) sobre el concepto del barroco: "Barroco, adjetivo, en arquitectura es una modalidad del bizarro; es, si se quiere así, el refinamiento... el abuso... es el superlativo del abuso. La idea de lo barroco trae consigo aquella de lo ridículo al exceso." Estos influjos múltiples son la causa de que se encuentren también muchos elementos humanistas en los poetas barrocos, aunque el sentido harmónico y rígidamente formal del latinismo humanista forme un contraste absoluto con la actitud del 
barroquismo. Carlos González Peña cita en su Historia de la literatura mexicana las palabras del Fr. Juan de Grijalba, quien decía en el siglo XVII: "Generalmente hablando son los ingenios tan vivos que a los once o doce años leen los muchachos, escriben, cuentan, saben latín y hacen versos como los hombres famosos de' Italia." Por eso no sería correcto decir que el conocimiento de los escritores clásicos no podia enfrenar ciertas aberraciones del barroquismo: al contrario, la literatura antigua fué puesta al servicio del pensamiento barroco, enriqueciendo en cierta manera la amplia cultura y la erudición profunda de los autores. Otro elemento característico del barroco lo constituyen los motivos bíblicós. El Cantar de los Cantares, Los Salmos, los milagros del Nuevo Testamento, sirven de alegorías, y el simbolismo llega a ser una forma de expresión particularmente favorecida por el barroquismo. Sería una tarea muy interesante investigar la evolución, desde el misticismo español en el siglo de oro hasta el período del barroco mexicano. Las poesías múltiples dedicadas a la Virgen de Guadalupe - por ejemplo aquella de Luis de Sandoval y Zapata- demuestran el ademán nuevo: en medio de un misticismo genuino, profundo, aislado, se encuentra un alegorismo, un simbolismo más o menos superficial, externo, culterano, tratando de conciliar lo Santo y lo misterioso con las tradiciones de la mitología pagana y de la poesía grecorromana. Lo que González Peña refiere en su obra arriba citada sobre José López Avilés, capellán del Virrey Fr. Payo Henríquez de Rivera, puede servir de prueba de nuestra teoría: "Este gran padre de las musas publicó en 1669 un pavoroso tomo en folio de versos latinos en alabanza de la Virgen de Guadalupe."

Una contribución enorme al barroquismo ha sido dada por la Iglesia católica. El catolicismo, internacional o más bien supernacional en sus raíces, ha creado aquel estilo típico en el siglo XVIr que solemos llamar estilo jesuítico. (La iglesia de Jesús en Roma ofrece el mejor ejemplo de este tipo que verdaderamente representa una nueva mentalidad.) La unidad de la Iglesia y del Estado, de la religión y de la política en la España de Felipe II, crea el fundamento de un desarrollo que influye decisivamente así en la arquitectura mexicana como en su literatura. Fué el erudito Werner Weisbach quien caracterizaba lo barroco como la expresión típica de la Contrarreforma. Introduciendo el concepto "barroquismo" en la literatura, llegamos a un resultado muy diferente del que se ex- 
presa generalmente sobre la literatura de los siglos XVI y XVII: el gongorismo, el culteranismo y el conceptismo permanecen como fenómenos de una decadencia literaria y de una aberración estilistica, pero no representan una decadencia del renacimiento, sino más bien del barroquismo. El influjo de la Iglesia pertenece al barroquismo y tho a la era de la decadencia. "Los jesuitas fueron cabalmente los campeones de la Contrarreforma, y, como consecuencia de su posición, hubieron de abrir nuevos caminos a la vida y al arte, y ellos fueron asimismo los que durante un siglo en Italia, Francia y Alemania propagaron y fomentaron el magnifico florecimiento de la arquitectura barroco-eclesiástica, que todavia hoy nos causa admiración y entusiasmo." (Ludwig Pfandl.)

¿Cuál es el último fin del barroco? Si logramos hallar una fórmula que explique la "Quintaesencia" del barroquismo, podemos esperar acercarnos otro paso a nuestro problema literario. Se ha dicho (Herbert Cysarz) que la era barroca trata de pintar en todas sus emanaciones. Los edificios son pinturas en piedra, y nuestro juicio sobre el lenguaje conceptista de Sigüenza y Góngora, de Sor Juana, de Pedro Muñoz de Castro sería más justo, si siempre tuviésemos en cuenta que los poetas trataron de crear más bien una pintura que tuna combinación de palabras. Estribando en aquella definición del barroquismo como intención de transformar las manifestaciones del espíritu humano en movimientos pintorescos, llegamos a un entendimiento más intensivo de muchos fenómenos literarios y particularmente de muchos títulos de libros que sin aquella interpretación nos parecen ridículos e hinchados, como por ejemplo el título del escritor mexicano del principio del siglo XVIII Pedro Muñọ de Castro: "Ecos de las Cóncavas del Monte Carmelo y resonantes balidos tristes de las Raqueles ovejas del aprisco del Elias carmelitano sol con cuyos ardores derretidos en llanto sus hijas las religiosas carmelitanas de México lamentan la pérdida de su amantísimo benefactor el Exmo. Sr. D. Fernando de Lancastre Norona y Silva, Virrey que fué desta Nueva España."

Una investigación de los títulos de las obras publicadas en este período, nos llevaría a resultados inesperados y muy interesantes: estos títulos nos indican más de lo que los autores intentaron. Nos demuestran que están dominados por la idea del canto, así como los poetas griegos de la época helenística del primer siglo A. C. quisierón ver acompañados sus poemas con la lira y el arpa. A veces las poe- 
sías barrocas, particularmente las de Alemania, España y México, semejan modernas pinturas expresionistas, reflejando el mismo placer del autor en el juego de palabras y de retruécanos como aquéllos gozan del juego de los colores. A veces las poesías del barroquismo parecen un corazón, una palma, un arpa: la idea de la pintura prevalece. Por eso entendemos por qué ciertas poesías del mismo autor -como por ejemplo las redondillas de Sor Juana- demuestran una sencillez maravillosa, mientras que otras están recargadas de expresiones conceptistas. La circunscripción predomina. Como en el barroco alemán las flores llegan a ser "linternas campestres", la yerba un "ataúd de los cuidados pálidos", las lágrimas "perlas y cristales", así se cambian en la lengua de Sor Juana los ojos en "luz hermosa", el pecho en "obediente acero"; en la lengua de Sigüenza y Góngora el cabello en una "emulación del Tíber", el nombre de Dios en "Sacro Numen". Lo que dice Cysarz sobre el barroco alemán puede ser aplicado con las mismas palabras a la poesía barroca mexicana: "Para entender plenamente la poesía barroca, se debe leerla al mismo tiempo con imaginación y con inteligencia: se debe abrir al juguete y a lo extraño, como al desengaño y al juicio final."

Parece que el barroquismo tiene la tendencia de substituir un arte por otro. Lo que hemos dicho de la pintura como parte esencial de la poesía barroca, puede decirse también de la música. Incluyendo este ramo de las artes en el alcance de nuestras observaciones, podemos decir que llegamos a resultados más justos y más correctos si suponemos que el intento de la mayor parte de los poetas barrocos fué la creación de una obra musical. No es accidental el hecho de que una gran cantidad de poesias. del siglo XVII tengan el título de "canciones". Volvemos a mencionar el nombre del jesuíta Matías de Bocanegra, cuya "Canción al desengaño" demuestra - no sólo en su título- el intento del poeta de despertar en el lector asociaciones musicales. La popularidad de esa canción fué tanta, que halló muchas imitaciones que se titulan todas "canciones", como por ejemplo aquella de don Bartolomé Fernández Talón bajo el título "canción moral", en que "de la belleza efímera de las rosas se sacan documentos floridos para despreciar la humana belleza de las mugeres" (1652). Menéndez y Pelayo cita en su Historia de la poesía hispanoamericana otros ejemplos muy característicos, entre ellos la "Canción famosa a un desengaño" por el padre don Manuel Antonio 
Valdés y Munguía, la "Canción a un desengaño" por Joseph Manuel Colón Machado, y la "Canción famosa a la vista feliz de un desengaño" por don Thomas Cayetano de Ochoa y Arin, y una "famosa canción a un desengaño" de autor anónimo. Casi todas estas canciones al desengaño respiran el mismo espíritu:

Una alegre mañana
En que el florido Abril con pompa vana
Del Imperio de Flora
Entregó al Mayo la primera Autora...
Una noche sombría,
Funesta emulación del claro día,
En palacios de espuma bulliciosa,
Duerme al compás de roncos caracoles...

Se ve que todos los títulos de aquellas obras llevan la palabra "desengaño"; pero quien someta el barroquismo a una investigación desde el punto de vista de una crítica de todos los fenómenos culturales dominantes en aquella época, vendrá al resultado de que esta referencia al desengaño no. es sorprendente. Pertenece el concepto del desengaño a los sentimientos fundamentales del barroquismo, y desengaño, desilusión, melancolía profunda, forman una parte de los sentimientos de aquella época, así como exageración, tempestuosidad, vehemencia y exceso de alegria forman la otra. Desde la obra maestra de Calderón, el carácter problemático de la vida llega a ser evidente. Mientras que para los místicos la vida terrestre tenía el carácter de una transición al otro mundo, de un período de preparación y de prueba, el poeta barroco consideraba la vida como un sueño, una sombra vana. (cf. Ludwig Pfandl.) ¿ No podemos construir sin artificialidad una conexión entre el entusiasmó del barroquismo por canciones y por sueños, y la teoría de Schopenhauer, según la cual la música representa la creación más perfecta del espíritu humano, porque adormece la voluntad y su avidez? Todos estos elementos se hallan en las obras de Sor Juana. Haciendo un análisis estilístico de cualquier soneto de la poetisa, encontramos todos los elementos que hemos enumerado como esenciales de lo barroco. En el primer verso del primer soneto se encuentra el concepto "engaño colorido". La poetisa menciona "de los años los horrores", y el último verso nos da una prueba ejemplar por el predominio del desengaño en la 
acumulación de los vocablos unidos solamente por el verbo auxiliar:

$$
\text { Es cadáver, es polvo, es sombra, es nada. }
$$

En su "Romance que en sentidos afectos produce el dolor de una ausencia", hallamos los versos siguientes :

$$
\begin{aligned}
& \text { Mira cómo el cuerpo amante, } \\
& \text { Rendido a tanto tormento, } \\
& \text { Siendo en lo demás cadáver, } \\
& \text { Sólo en el sentir es cuerpo, }
\end{aligned}
$$

versos que habrían sido imposibles en la boca de Santa Teresa. La tendencia de ofrecernos una pintura es evidente, y esta pintura asume los mismos trazos terribles y odiados que encontramos en la plástica y en la pintura de estas décadas. En las "Endechas" de Sor Juana "que espresan cultos conceptos de afecto singular", hallamos los versos siguientes:

\section{Díganlo las ruinas \\ De mi valor deshecho \\ Que en contritas cenizas \\ Predican escarmientos.}

Ruinas y cenizas son los mismos conceptos que asumirán una significación eminente en el romanticismo, alzándose a principios del siglo XIX. En la introducción a las Obras escogidas de Sor Juana, la elección de las cuales estuvo a cargo de P. Henríquez Ureña, con la colaboración de Patricio Canto, se encuentra aquella referencia al barroquismo que, como hemos mencionado antes, falta generalmente en la mayor parte de las investigaciones que ven solamente decadencia y aberración en este periodo. Contiene un alegato de Karl Vossler que dice en su ensayo "La décima musa de México":

Su cultura teológica y literaria, su arte todo, pertenecen al barroco español y revelan lo afectado, el rasgo marchito de tiempos tardios; no obstante, en su resuelto modo de vivir y en el afán infatigable de queree comunicarse se siente la frescura juvenil de la altiplanicie mexicana. 
Desde nuestra posición frente al barroquismo no podemos consentir con un juicio del autor de esa introducción, según el cual la comedia mitológico-galante, antiguo-barroca; Amor es más laberinto -escrita por Sor Juana en colaboración con su primo el licenciado Juan de Guevara-, "no tiene ningún estilo." Más bien, según nuestra interpretación de aquel período, hemos de decir que el estilo de aquella comedia es barroco, ni más ni menos. Pero es correcto decir que si quería "el arte barroco español de los últimos tiempos deslumbrar al mundo todo, hastiado y cansado, la poesía de Sor Juana es el asombro del espíritu que despierta, hambriento, y se esfuerza en su ansia de saber". Llegamos a la conclusión de que el lenguaje de la música expresa lo mismo que el de los pintores barrocos, de Ribera y de Zurbarán, de Velázquez y del Greco, de los Poussin, Claude Lorrain, Van Dyck, Ruisdael y Rembrandt, y que existe una unidad superior bajo la cual la poesía se coordina con aquellas artes.

III

Volvamos a nuestro punto de partida, al examen de la cuestión sobre cuáles sean los elementos característicos del barroco. Dice Heinrich Woelfflin que "lo ilimitado" constituye uno de los momentos esenciales del barroco. Mientras que el renacimiento ofrece la obra de arte en su suma sencillez, el barroco tiene la tendencia a multiplicar los fenómenos. En esa nostalgia, en ese anhelo de tocar los límites de la eternidad, vemos otra confirmación de nuestra opinión sobre la tendencia de la poesía barroca. Hemos hablado de los títulos retumbantes de la mayor parte de esta poesía. Tomemos como otro ejemplo a don Carlos de Sigüenza y Góngora, sobrino del Góngora español. Quizás nadie ha sido culpado más que él por su "manera gongorizante". Su obra El Mercurio Volante contiene un ensayo contemporáneo de la primera penetración eficaz de los españoles en México después de la rebelión de Puebla en 1680. Pero la lengua de esa obra es nada menos que la lengua de un historiógrafo. Escuchemos unas palabras de la arenga de un general a sus soldados:

A Indios a perros, $y$ de la más mala ralea que calienta el Sol, pensais que ha sido miedo de vaestra multitud, $Y$ armas mi tolerancia? Lastima ba sido la que os he tenido para no mataros, 
pues d'un sólo amago mio perecierais todos. Que es esto! Con quien hablo? Aun teneis las armas en las manos viendome airado? Como siendo Cristianos; pero, tan malos, que faltando a lo prometisteis en el baptismo, profanasteis la Iglesia, destruisteis las Imagenes, disteis muerte a los Religiosos, y os sacrificasteis al Demonio, para vuestro daño, no os arrojais por ese suelo con humildad, adorais la verdadera Madre de vuestro Dios, y mío, que en la Imagen con que se ennoblece este Estandarte Real os viene a combidar con el perdon, para que vayais al Cielo. Hincaos, hincaos sin dilación, antes que con el fuego de mi indignación os abrase a todos.

¿Qué es esa arenga si no una erupción genuina de lo barroco? $\mathrm{Y}$ el título mismo, El Mercurio Volante, con su alusión al Dios pagano y con su tendencia dirigida hacia el cielo, ¿no aparece ante nuestros ojos en una luz diferente, si lo consideramos como expresión concentrada de una idea barroca?

La idea barroca invade la esfera privada del hombre, conquistando muchas veces toda la personalidad. Entre el hombre del barroco y los hombres de las épocas precedentes y de las siguientes, hay una diferencia absoluta y esencial, no gradual, como entre el hombre del periodo humanista y del romanticismo. El hombre barroco tiene la tendencia a abrazar el universo. A mentudo nos preguntamos: ¿Cómo es posible que un mismo hombre pudiese ser poeta, filósofo, matemático, astrónomo, historiador y todo eso con eficacia y éxito? Este fenómeno singular se explica solamente desde un punto de vista metafísico: es un ademán que trata de romper los vínculos terrestres, es una actitud que conoce un solo anhelo: el de alcanzar las estrellas. La misma tendencia universal se demuestra en el "Triumpho Parthenico que en glorias de Maria Santissima inmaculadamente concebida, celebró la Pontificia, Imperial y Regia Academia Mexicana en el Biennio, que como su rector la governó el Doctor Don Juan de Narváez, Tesorero General de la Santa Cruzada en el Arçobispado de México, y al presente Cathedratico de Prima de Sagrada Escritura. Describelo D. Carlos de Sigiienza y Góngora, mexicano y en ella Cathedratico proprietario de Mathematicas". Esta obra es una compilación de poemas premiados en certámenes de los años 1682 y 1683 . Miremos el soneto que fué premiado por los jueces:

Este, que más que al pórfido luciente Deve su eternidad a la hermosura 
Panegyrico siendo a su estructura

Letras, que en él clausula el occidente:

Este docto Athenas, a quien ardiente

De corona le sirve-la que apura

Cuantas inundaciones de luz pura

Con lluvias de esplendor causa Oriente:

Mas que gloria fugaz, delphyca pyra

Joven heroyco, a tu esplendor se ofrece

Que avaro das, y prodigo atesoras:

En ella si tu edad cón su edad crece

Para lo eterno a que tu nombre aspira

Aguila es poco, Fenix te mejoras.

Otra obra de Sigüenza y Góngora, Teatro de Virtudes Politicas que constituyen a un Principe, título del cual por falta de espacio reproducimos aquí solamente una mínima parte, fué sometida a Sor Juana crítica. La obra fué sumamente elogiada de la jeronimita, y ella contestó con un soneto tan barroco que queremos citar al menos la primera estrofa:

\author{
Dulce, canero Cisne Mexicano, \\ Cuya voz, si el Estigio lago oyera \\ Segunda vez Euridice te diera \\ $\mathrm{Y}$ segunda el Delfin te fuera humano...
}

Siempre volvemos a hacer la misma observación: mitología y clasicismo -clasicismo, pero en un sentido completamente diverso de aquel del humanismo- juegan un papel enorme en la literatura, en la correspondencia, en todo el ademán, como hemos hecho constar.

La estima de Sigüenza por su célebre contemporánea no es menor que la de Sor Juana por Sigüenza. Entre numerosas alabanzas de Sor Juana, encontramos la siguiente que citamos a causa de su exageración barroca. Dice: "que en un solo individuo goza Mexico lo que en los siglos anteriores repartieron las gracias a cuantas doctas mujeres son asombro venerable de las historias". Para demostrar lo patético en la evolución del pensamiento barroco, queremos citar la poesía XXXIV de la Primavera Indiana del Poema Sacro-Histórico de Sigüenza: 
Organiza del ayre mas lacido

Un armonico cuerpo el Angel bello,

Embidias del Abril era el vestido,

Emulación del Tiber el cabello:

Un volante de luces embestido

Aprisiona en el terso eburneo cuello,

Dando en su rostro alvergue placentero

Al rojo Mayo, y al nevado Enero.

El espiritu del barroco puede manifestarse solamente en lo elevado. Woelfflin, en su investigación del renacimiento y del barroco, cita lo que ha dicho Carl Justi sobre Winckelmann, el gran erudito de la era clasicista alemana del siglo XVIII: "Mesura y forma, sencillez y nobleza de la línea, quietud del alma y suave delicadeza - estos fueron los vocablos de su Credo, y el agua cristalina fué su símbolo favorecido". A tales palabras de Justi, añade Woelfflin: "Cambiando cada uno de estos conceptos en su opuesto, se alcanza la esencia del nuevo arte" (id est barroco).

Según la aclaración de Aristóteles, la poesía es más instructiva que la Historia, porque ésta se refiere a lo particular y aquélla a lo universal. Este pensamiento de Aristóteles, ha sido desarrollado en las obras de la época barroca. Lo que solemos calificar como pompa y magnificencia en el lenguaje y en la versificación de los siglos XVI y XVII, tiene que ser interpretado como tendencia hacia lo metafísico y lo universal. Luis Sandoval y Zapata, mencionado arriba, puede servir de ejemplo excelente por su tendencia metafísica. Don Francisco Pimentel cita uno de los sonetos de Sandoval, en el cual el autor compara la transformación de las flores en la àmagen de la Virgen, con la metamorfosis del fénix mitológico.

El astro de los pájaros expira,

Aquella alada eternidad del viento,

$Y$ entre la exhalación del movimiento

Victima arde olorosa de la pira

En grande boy metamórfosi se admira

Mortaja a cada flor; mas lucimientó

Vive en el lienzo nacional aliento

El ámbar vegetable que respira

Retratan a Maria sus colores:

Corre cuando del sol la luz las hiere

De aquestas sombras envidioso el día 
Mas dichosos que el fénix moris, flores: Que él para nacer pluma, polvo muere Pero vosotras para ser Maria.

En el presente soneto se encuentran todos los elementos que hemos calificado como característicos del barroco. No obstante la diferencia entre este soneto y el arriba dicho de Sor Juana, se hallan en ellos los mismos conceptos, hasta los mismos vocablos: eternidad y exhalación, mortaja y sombra, polvo y muerte - todas estas palabras sirven para explicar una idea: la de la transición y la fugacidad de nuestra vida, combinando este ademán con un fuerte afán de lo eterno. Bajo este punto de vista no podemos consentir con el juicio de Pimentel, que califica tal soneto como "de lo más disparatado y peor de la escuela gongorina, y las alabanzas demuestran más bien el gusto barroco de la época."

La aspiración a saberlo todo pertenece estrechamente al cuadro que hemos dibujado del barroco. Si Sor Juana no hubiese escrito ninguna estrofa en lenguaje barroco, la calificariamos barroca a causa de su apasionada voluntad de abrazar toda la sabiduria de su tiempo: aunque consideraba los demás ramos de las ciencias como auxiliares de la Teología (Pimentel) - lo que corresponde a la actitud general de los teólogos de aquella era-, estudió filosofía y literatura, matemáticas y física, retórica e historia y, sobre todo, lógica.

Desde el punto de vista de una crítica estética del estilo, es de sumo interés parangonar los juicios de los eruditos Pimentel y Woelfflin -que vienen de dos campos completamente diferentessobre el mismo fenómeno artístico. Woelfflin investiga la arquitectura del barroco en Italia, y Pimentel nos da una excelente historia crítica de la poesía en México. Tan diferentes como son los puntos de partida, así son los resultados. Pero a pesar de esta diferencia, los dos doctos poseen un común denominador: la investigación crítica de dos ramos importantes de la historia del espíritu humano en los siglos XVI y XVII. La diferencia de los puntos de partida condiciona la diferencia de los resultados: el descubrimiento de la idea fundamental del barroco como una nueva actitud, hasta como una nueva conducta del hombre, hace que gocemos de los fenómenos de esa ideología, mientras que la representación de las obras poéticas bajo el aspecto de su derivación desde ciertos fenómenos españoles de indubitable aberración y decadencia obscurece el cuadro 
histórico, dándonos solamente los aspectos negativos de un fenómeno literario que merece la valuación más profunda. Es verdad que el culteranismo consiste en la exageración de los privilegios poéticos. Pero no es menos verdadero que lo barroco consiste en la exageración de los privilegios arquitectónicos. Es verdadero que los poetas mexicanos de esos siglos toleran los retruécanos, los juegos de palabras; pero no es menos verdadero que la arquitectura en sus ornamentos explica la misma tendencia al juego, y sin embargo gozamos de tales ornamentos cuando hemos aprendido a entender este lenguaje. Es correcto decir que Ovidio demuestra los primeros trazos de lo que solemos llamar decadencia de la literatura latina. Pero ¿quién no leería sus obras con la más profunda admiración, con el más intenso deleite? Lo que parece obscuro y sobrecargado de adornos, se despliega en plena belleza al ojo que es propenso a desatar sus enigmas. No se puede decir que al barroco le faltan las ideas, la inspiración y el sentimiento: se tienen que descifrar los jeroglíficos de este idioma nuevo. La consecuencia de la falta de comprensión del espíritu del barroco, es una interpretación errónea hasta de los sentimientos de aquella era. Se ha dicho que las rimas amorosas de Sor Juana son frías, escritas sin sentimientos genuinos. Desde nuestro punto de vista, el problema de la expresión de los sentimientos acepta un aspecto diverso: los sentimientos no están ausentes, sino expresados de una manera diferente de aquella que predominó durante el renacimiento y que predominará en el rococó y en el romanticismo. Los autos sacramentales de Sor Juana ofrecen, en su sencillez de lengua y de pensamientos, una prueba de nuestra teoría de que a aquella época no le faltó el sentimiento ni el calor, sino que los suyos son el sentimiento y el calor de la época barroca.

Hemos dicho que el barroquismo no influyó sólo en la personalidad humana en su ademán artístico, sino también en su conducta personal. Creemos haber hecho una observación psicológica muy interesante: la mayor parte de los críticos e historiógrafos observan un desgarrón que hiende la personalidad en dos partes diferentes; no pueden explicarse cómo los poetas de los siglos XVI y XVII pueden unir en su personalidad religiosidad y desengaño, sencillez y exageración, sentimiento y rigidez. En todas las biografías de Sor Juana leemos, como señal característica de su personalidad extravagante, la explicación que ella misma da a su cuidado: 
"Que siendo así que en las mujeres ( $y \backslash$ más en tan florida juventud) es tan apreciable el adorno natural del cabello, yo me cortaba de él cuatro o seis dedos, midiendo hasta donde llegaba antes, e imponiéndome ley de que si cuando volviese a crecer hasta alli, no sabía tal o cual cosa que me había propuesto aprender en tanto que crecía, me lo había de volver a cortar en pena de la rudeza... que no me parecía razón que estuviese vestida de cabellos cabeza que estaba tan desnuda de noticias, que eran más apetecible adorno". Nosotros no vemos en este hecho una extravagancia o una seña de decadencia o de aberración. No nos asombramos siquiera de semejante conducta; para nosotros no es un fenómeno singular y personal de una entusiasta, sino un fenómeno que se puede entender en su significación interna y real solamente desde un punto de vista sociológico: es la conducta genuina de una contemporánea del barroco. Sea que admiremos esta conducta como un indicio de vigor. interno, o sea que la desechemos, de ninguna manera podemos decir que esa conducta no sea ingenua. $\mathrm{El}$ punto de vista sociológico nos da la posibilidad de unir sin dificultades artísticas y psicológicas, lo que desde cualquier otro punto de partida pareció ser incompatible. Hasta aparentes contradicciones se resuelven en una armonía que a su vez significa muchísimo para el mejor entendimiento de los problemas literarios.

No fué el intento de este artículo crear una nueva teoría literaria. Más bien fué el de ofrecer a todos los interesados en problemas literarios una norma que nos abre un camino nuevo, una avenida que no nos conduce a la negación, sino al gozo serio de un fenómeno que a veces nos parece extraño y aun antipático, aunque es siempre interesante y valioso. Quien sea capaz de gozar de una catedral barroca, será capaz de gozar asimismo de una poesía barroca, que no se explica suficientemente con las denominaciones de gongorismo o conceptismo, de decadencia o de transición, sino que se desarrolla en la plena luz de una nueva evolución del espíritu humano: el del barroco.

Werner Peiser,

Loyola Üniversity, New Orleans, La. 


\section{BIBLIOGRAFIA}

Abreu Gómez, Ermilo, La ruta de Sor Juana. México, 1938.

Barreta, Isaac J., Litetatura hispanoameticana. Quito, Ecuador, 1934.

Bergner, H., Das Barocke Rom. Leipzig, 1914.

Calleja, P. Diego, S. J., A la muerte del Fénix de México. Lisboa, 1701.

Cruz, Juana Inés de la, Obras escogidas. Espasa-Calpe Argentina, 1938.

Cruz, Juana Inés de la, Los Empeños de una Casa. México, 1940.

Cysarz, Herbert, Vor-und Fruchbarock. Leipzig, 1937.

Delacroix, Henri, Le Language et la Pensée. Paris, 1930.

González Peña, Carlos, Historia de la literatura mexicana. México, 1940.

Hatzfeld, Helmut, "El predominio del espíritu español en la literatura europea del siglo XVII", Revista de Filologia Hispánica, III, 1941.

Justi, Carl, Winckelmann und seine Zeitgenossen. Leipzig. 1923.

Leonard, Irving A., Don Carlos de Sigüenza y Góngora. Berkeley, Cal., 1929.

Menéndez y Pelayo, Marcelino; Historia de la poesia hispano-americana. Tomo I. Madrid, 1911.

Nervo, Amado, Juana de Asbaje. Madrid, 1910.

Northup, George T., The Picaresque Novel. New York, 1935.

Pfandl, Ludwig, Geschichte der Spanischen Nationalliteratur in ihrer Bluetezeit. Freiburg, 1929.

Pimentel, Franciseo; Obras completas. Tomo IV, México, 1903.

Schons, Dorothy, Nuevos datos para la vida de Sor Juana Inés de la Cruz. México, 1929.

Sigüenza y Góngora, Carlos, Obras. México, 1928.

Sigüenza y Góngora, Catlos, El Mercurio Volante. Los Angeles, 1932.

Torres-Rioseco, Arturo, Antologia de la literatura bispanoamericana. New York, 1941.

Toussaint, Manuel, "Prólogo" a Obras escogidas de Sor Juana Inés de la Cruz. México, 1928.

Toussaint, Manuel, Paseos coloniales. México, 1938.

Vossler, Karl, La Décima Musa de Méjico. 1934.

Weisbach, Werner, Der Barock als Kunst der Gegenteformation. Berlin, 1921.

Weisbach, Werner, Det Manierismus, Zeitschrift fuer Bildende Kanst, 1919.

Woelfflin, Heinrich, Die Klassische Kunst. Muenchen, 1924.

Woelfflin, Heinrich, Renaissance und Barock. Muenchen, 1926.

Biblioteca de Autores Españoles. Tomo 45. Madrid. 1924.

Dictionnaire Historique de L'Atchitecture. (Quatremère de Quincy), 1795-1825.

Outline History of Spanish Literature, F. S. Crofts. New York, 1941.

Antología de Poetos Hispano-Ameticanos, Real Academia Española. Tomo I. Madrid, 1893. 
